\title{
Hazard assessment of a silver nanoparticle in soil applied via sewage sludge
}

\author{
Karsten Schlich ${ }^{*}$, Thorsten Klawonn ${ }^{1}$, Konstantin Terytze $^{2}$ and Kerstin Hund-Rinke ${ }^{1}$
}

\begin{abstract}
Background: Silver nanoparticles (AgNPs) are widely used in many fields of application and consumer products due to their antibacterial properties. The aim of this study was to prepare a hazard assessment for one specific AgNP in soil, incorporated via sewage sludge (the sewage sludge pathway). The effects of pristine AgNPs on microorganisms, plants and earthworms were first determined in screening tests. Long-term tests over 140 days were then conducted with AgNPs added to soil via sewage sludge. AgNPs were incorporated into the sludge through a simulated sewage treatment plant (STP) over 10 days to allow transformation to occur and also by manual spiking over $2 \mathrm{~h}$. The results of the most sensitive organism from the long-term tests, the soil microorganisms, are presented.

Results: The STP simulations confirmed that at environmentally relevant concentrations $>90 \%$ of AgNPs remain bound to sewage sludge. Effects of AgNPs bound to sewage sludge and added to soil were similar to that of pristine NM-300K after degradation of the sludge. The predicted no-effect concentration for NM-300K in soil of 0.05 $\mathrm{mg} / \mathrm{kg}$ dry soil determined a maximum threshold of $30 \mathrm{mg} / \mathrm{kg}$ dry sludge per application, considering the maximum addition of sewage sludge in Germany ( 5 tons per hectare every 3 years).

Conclusion: At environmentally relevant concentrations, AgNP absorption to sludge and aging in soil (even after transformation) cause toxic effects on soil microorganisms of the terrestrial ecosystem.
\end{abstract}

Keywords: Hazard assessment; Silver nanoparticles; Ecotoxicology; Soil; Sewage sludge

\section{Background}

Silver nanoparticles (AgNPs) are used in a wide field of applications, e.g. plastics, textiles, health care, building facades and appliances, due to their antibacterial properties. According to 'An inventory of nanotechnologybased consumer products currently on the market' (The Project on Emerging Nanotechnologies), AgNPs are used in more than 313 commercial products [1].

The increasing and varied use of AgNPs also increases the risk of the release of these particles from products into the environment. Calculations considering the environmental exposure to AgNPs, based on a material flow analysis of the life cycle of various nanoparticles, suggest that aquatic organisms may be harmed by AgNPs present in the effluent of sewage treatment plants (STPs) [2].

\footnotetext{
* Correspondence: karsten.schlich@ime.fraunhofer.de

${ }^{1}$ Fraunhofer Institute for Molecular Biology and Applied Ecology, Auf dem Aberg 1, Schmallenberg 57392, Germany

Full list of author information is available at the end of the article
}

Numerous studies on the toxicological effects of AgNPs on organisms in the aquatic environment have shown that pristine AgNPs provoke strong toxic effects on fish [3-5], daphnids [6] and algae [7]. Toxic effects on organisms of terrestrial ecosystems are also reported, e.g. on earthworm reproduction [8-10] and microbial biomass and enzyme activity in soil [11]. These studies provide important information for risk characterisation.

In the context of life cycle assessment and risk characterisation of AgNPs, the main focus is the quantity and how AgNPs become free of the products that contain them (e.g. textiles and wall facades). Numerous studies show the release of AgNPs from textiles [12,13], silver nanoparticle-containing washing machines [14] and facades [15]. Release into the surrounding environment results in changes to AgNP properties and their effects on terrestrial and aquatic organisms. As a result, it is difficult to perform a risk characterisation without including possible modifications and transformation processes from the pristine nanoparticulate form [16]. The release 
of AgNPs into the environment commonly occurs via point source accumulation in sewage sludge (the end product of sewage treatment) that is applied as an agricultural fertiliser. In Germany, 2 million tons of dry sewage sludge solids from municipal wastewater treatment plants is produced annually. Around 30\% of this sludge is used for farmland application. In Spain, Portugal, France and the UK, the majority of sewage sludge produced is applied to agricultural land [17].

The main aim of this study was to prepare a hazard assessment of the AgNP NM-300K (from the Organisation for Economic Co-operation and Development (OECD) Sponsorship Programme [18]) in soil, incorporated via sewage sludge. The focus is the entry of the AgNP (NM-300K), which was absorbed into the sludge during the sewage treatment phase and then applied as an agricultural fertiliser on farmland. Because the predicted environmental concentration (PEC) for NM-300K was unavailable, the preparation of a classic risk characterisation with the ratio of PEC and predicted no-effect concentration (PNEC) was not possible.

To achieve the aim, we (1) investigated the effects of pristine NM-300K on soil microorganisms by examining potential ammonium oxidation, microbial biomass and functional microbial diversity and (2) determined the effects on microorganisms of sewage sludge in a respiration inhibition screening test and simulations of a STP. The simulation of the STP involved spiking sewage sludge with NM-300K and silver nitrate over 10 days and a shorter application by stepwise dosing of AgNPs into sewage sludge over $2 \mathrm{~h}$.

Subsequently, (3) long-term experiments over 140 to 180 days simulated the realistic entry of NM-300K and silver nitrate via sewage sludge into soil when applied as a fertiliser. STP simulation allowed the nanoparticles and ions to be exposed to possible transformation reactions, thus providing maximum environmental relevance. Each experiment utilised silver nitrate as a pure silver ion source to compare the effects and fate of silver nanoparticles and silver ions. Finally, we (4) conducted a hazard assessment to determine the maximum concentration of AgNPs in sewage sludge that would result in no effects on organisms of the terrestrial ecosystem.

\section{Results}

\section{Ecotoxicological effects of NM-300K and silver nitrate on soil microorganisms \\ Potential ammonium oxidation}

In all ammonium oxidation tests, the validity criterion (coefficient of variation between replicates of control $\leq 15 \%$ ) was fulfilled. The transformation of ammonium is expressed as nitrite production. No effect due to NM-300K DIS (the dispersant) on nitrite production was observed after $24 \mathrm{~h}$ or 7 days. Nitrite production was significantly inhibited by the pure dispersant $(11.7 \%)$ after an incubation period of 28 days. The observed effect is not considered an effect indicator of the dispersant as the percent inhibition was smaller than the accepted percent variance for replicates of the control (validity criterion).

Nitrite production was inhibited throughout the experiment, and NM-300K concentration-effect relationships were demonstrated. Inhibition increased from the first point of measurement at $24 \mathrm{~h}$ until the end of the test after 28 days. Statistical differences were found even at the lowest soil concentration of $0.56 \mathrm{mg} / \mathrm{kg}$ dry soil for NM-300K. The inhibitory effect of NM-300K increased with the duration of the test, e.g. from $25.1 \%(24 \mathrm{~h})$ to $28.2 \%$ (7 days) to $45.4 \%$ (28 days) at a concentration of $1.67 \mathrm{mg} / \mathrm{kg}$ dry soil (Additional file 1: Table S2). After 28 days, the NM-300K no-observed-effect concentration (NOEC) was $<0.56 \mathrm{mg} / \mathrm{kg}$ dry soil and the effective concentration at $10 \%$ inhibition $\left(\mathrm{EC}_{10}\right)$ was $0.5 \mathrm{mg} / \mathrm{kg}$ dry soil (Table 1).

Silver nitrate caused no inhibition of nitrite production in the 0.19 and $0.56 \mathrm{mg} / \mathrm{kg}$ dry soil treatments. Instead, a stimulatory effect occurred but was only significant after 7 days at $0.19 \mathrm{mg} / \mathrm{kg}$ dry soil (19.4\%, Additional file 1: Table S2). After 28 days, the silver nitrate NOEC was $0.56 \mathrm{mg} / \mathrm{kg}$ dry soil and the $\mathrm{EC}_{10} 1.4 \mathrm{mg} / \mathrm{kg}$ dry soil (Table 1). The inhibitory effects of NM-300K and silver nitrate were comparable at concentrations of 1.67 to 15 $\mathrm{mg} / \mathrm{kg}$ dry soil, as silver nitrate caused $25.5 \%$ to $90.0 \%$ inhibition in nitrite production and NM-300K $25.1 \%$ to 85.9\% inhibition (Additional file 1: Table S2). The effect of NM-300K slightly increased over a period of 28 days, while the effect of silver nitrate was comparable at all three points of measurement.

\section{C-transformation}

In both microbial biomass tests, the validity criterion (coefficient of variation between replicates of control $\leq 15 \%$ ) was fulfilled. Investigations into the differences between controls with and without dispersant for NM-300K indicated no difference; thus, the results presented here are in comparison to the control without dispersant.

After $24 \mathrm{~h}$, no significant difference in biomass was observed between the control and soils containing NM300K (Additional file 2: Table S3). After 7 days, microbial biomass decreased by $39.9 \%$ and $73.2 \%$ at the lowest and highest NM-300K concentrations, respectively (Additional file 2: Table S3), indicating a concentrationeffect relationship. The $\mathrm{EC}_{10}$ is $<0.56 \mathrm{mg} / \mathrm{kg}$ dry soil (Table 1). After 28 days, microbial biomass was inhibited by $10.9 \%$ at the two lower concentrations and $55.7 \%$ and $78.1 \%$ at the two higher concentrations (Additional file 2: Table S3). A NOEC of $1.67 \mathrm{mg} / \mathrm{kg}$ dry soil and an $\mathrm{EC}_{10}$ of $1.0 \mathrm{mg} / \mathrm{kg}$ dry soil for $\mathrm{NM}-300 \mathrm{~K}$ were calculated (Table 1). 
Table 1 NOEC and $\mathrm{EC}_{10}$ from tests with NM-300K and silver nitrate

\begin{tabular}{|c|c|c|c|c|c|c|c|}
\hline & & Potential amn & ium oxidation & Microb & jiomass & Respir & n inhibition \\
\hline & & $\begin{array}{c}\text { NOEC } \\
\text { (mg/kg dry soil) }\end{array}$ & $\begin{array}{c}\mathrm{EC}_{10} \\
\text { (mg/kg dry soil) }\end{array}$ & $\begin{array}{c}\text { NOEC } \\
\text { (mg/kg dry soil) }\end{array}$ & $\begin{array}{c}\mathrm{EC}_{10} \\
\text { (mg/kg dry soil) }\end{array}$ & $\begin{array}{l}\text { NOEC } \\
(\mathrm{mg} / \mathrm{L})\end{array}$ & $\begin{array}{c}\mathrm{EC}_{10} \\
(\mathrm{mg} / \mathrm{L})\end{array}$ \\
\hline $3 \mathrm{~h}$ & NM-300K & - & - & - & - & $<9$ & 27.9 \\
\hline & & & & & & & (24.0 to 30.0 \\
\hline & Silver nitrate & - & - & - & - & $<1$ & 1.1 (n.d.) \\
\hline $24 \mathrm{~h}$ & NM-300K & $<0.56$ & 0.6 & $>15.0$ & n.d. & - & - \\
\hline & & & (0.0 to 1.3 ) & & & & \\
\hline & Silver nitrate & 0.56 & 0.9 & $<0.19$ & n.d. & - & - \\
\hline & & & (0.6 to 1.2 ) & & & & \\
\hline 7 days & NM-300K & $<0.56$ & 1.1 & $<0.56$ & n.d. & - & - \\
\hline & & & (n.d. to 1.7 ) & & & & \\
\hline & Silver nitrate & n.d. & 1.2 & 5.0 & 2.5 (n.d.) & - & - \\
\hline & & & (0.8 to 1.5 ) & & & & \\
\hline 28 days & NM-300K & $<0.56$ & 0.5 & 1.67 & 1.0 (n.d.) & - & - \\
\hline & & & (0.0 to 1.0 ) & & & & \\
\hline & Silver nitrate & 0.56 & 1.4 & n.d. & n.d. (n.d.) & - & - \\
\hline & & & (1.2 to 1.6$)$ & & & & \\
\hline
\end{tabular}

(x) $95 \%$ confidence interval, n.d. not determined.

Significant inhibition of microbial biomass after $3 \mathrm{~h}$ by silver nitrate indicated a concentration-effect relationship. At $0.19 \mathrm{mg} / \mathrm{kg}$ dry soil, inhibition was $19.9 \%$, ascending to $76.8 \%$ at $15 \mathrm{mg} / \mathrm{kg}$ dry soil (Additional file 2: Table S3). After 7 days, the response was reversed to a stimulation effect. Biomass stimulation increased from $12.3 \%$ to $25.1 \%$ as the silver nitrate concentration increased, and only at the highest concentration of silver nitrate $(15 \mathrm{mg} / \mathrm{kg}$ dry soil) was a significant inhibition effect (50.3\%) observed (Additional file 2: Table S3). After 28 days, the microbial biomass was higher in all silver nitrate treatments compared to the control; however, the biomass stimulation became less as the $\mathrm{Ag}$ concentration increased. At the lowest silver nitrate concentration of $0.19 \mathrm{mg} / \mathrm{kg}$ TM soil, the biomass increase was significant. A NOEC was not calculated at the end of the test with silver nitrate due to the reverse concentration-effect relationship.

\section{Ecotoxicological tests of pristine NM-300K and silver nitrate on sewage sludge microorganisms Respiration inhibition}

A respiration inhibition test with sewage sludge was conducted in accordance with the OECD Guideline 209 [19] to examine the effect of NM-300K and silver nitrate on the respiration of microorganisms in sewage sludge. Concentrations of $1,3,9,27,50,81$ and $100 \mathrm{mg} / \mathrm{L}$ were tested. In all tests, the validity criteria were fulfilled (variance of the controls: (a) variation from the mean $\leq 7.5 \%$, (b) variation $K_{\min }$ from $K_{\max } \leq 15 \%$ ).
At $50 \mathrm{mg} / \mathrm{L}, \mathrm{NM}-300 \mathrm{~K}$ inhibited respiration by $68.9 \%$, while at $100 \mathrm{mg} / \mathrm{L}$, inhibition was $100 \%$ (Additional file 3: Table S4). The $\mathrm{EC}_{10}$ for $\mathrm{NM}-300 \mathrm{~K}$ is $27.9 \mathrm{mg} / \mathrm{L}$ (Table 1). Silver nitrate had a stronger effect on the sewage sludge microorganisms. At $50 \mathrm{mg} / \mathrm{L}, 100 \%$ inhibition was found and $76.1 \%$ at $3 \mathrm{mg} / \mathrm{L}$ (Additional file 3: Table $\mathrm{S} 4)$. The $\mathrm{EC}_{10}$ for silver nitrate is $1.1 \mathrm{mg} / \mathrm{L}$ (Table 1 ).

Long-term effects of NM-300K and silver nitrate in soil using manually spiked sludge and sewage treatment plant simulation

Analytical measurements

After manual addition of AgNPs to sewage sludge, concentrations of 1.6 and $3.4 \mathrm{mg} / \mathrm{kg}$ dry soil (NM-300K) and 2.1 and $4.0 \mathrm{mg} / \mathrm{kg}$ dry soil (silver nitrate) were recovered. The standard deviation was high (Additional file 4: Table S5).

In comparison, the standard deviation was lower in the second long-term test where the test material was applied to the sewage sludge via the simulation of a sewage treatment plant. This indicates that NM-300K and silver nitrate were mixed homogeneously within the soil using sludge spiked via the STP compared to manually spiked sludge.

In the preliminary phase of the STP experiment, elimination of dissolved organic carbon (DOC) was $\geq 80 \%$ in all units. As a result, continuous addition of $\mathrm{Ag}$ into the STPs was started. In each STP simulation, over the entire experimental period, DOC elimination was $95 \%$ to $98 \%$. The degradation rate of DOC by the sludge microorgan- 
isms was not affected by the introduction of NM-300K or silver nitrate. Measurements of the Ag concentration showed that at all influent concentrations (0.04 to 1.6 $\mathrm{mg} / \mathrm{L}$ ) over a period of 10 days, the majority of NM-300K was accumulated in the sewage sludge. At the highest influent concentration of $1.6 \mathrm{mg} / \mathrm{L}, 82 \%$ to $100 \%$ of NM-300K was located in the sludge. Additionally, for the silver nitrate concentration of $0.4 \mathrm{mg} / \mathrm{L}, 87 \%$ to $100 \%$ of the silver remained in the sludge (Additional file 5: Table S6). For NM-300K, 0.3, 2.5, 5.2 and 9.0 $\mathrm{mg} / \mathrm{kg}$ dry soil were measured, while for silver nitrate, $3.4 \mathrm{mg} / \mathrm{kg}$ dry soil was recovered (Additional file 4: Table S5).

The $\mathrm{pH}$ decreased slightly over time with a faster decrease in samples containing sludge. For example, in test 1 , after 11 days pH 5.5 was measured in the control whereas in the sludge control and the two highest concentrations of $\mathrm{NM}-300 \mathrm{~K}$ and silver nitrate, $\mathrm{pH}$ values of 4.9 and 5.0 were recorded (Additional file 4: Table S5). Due to the fact that the $\mathrm{pH}$ values in the sludge control and the two highest soil concentrations were similar throughout the test, effects on microorganism activity were clearly related to either NM-300K or silver nitrate.

\section{Potential ammonium oxidation}

The criterion of validity was passed with $\leq 15 \%$ coefficient of variation between the replicates of the control at all measurement points for both spiked sludge and STP simulation. In all treatments with spiked sludge, the potential ammonium oxidation was inhibited after 11 days. The test system seemed to be disturbed by the introduction of sewage sludge, but no effects due to the test materials were observed (data not shown).

Comparing the controls with and without sludge of the test performed with manually spiked sludge (long-term test 1), nitrite production in the sludge control was stimulated through the addition of sewage sludge (32, 60 and 100 days); however, after 180 days, no significant difference was observed (Additional file 6: Table S7). For both NM-300K and silver nitrate, nitrite production was comparable to the sludge control after 32 and 60 days. Statistical differences compared to the sludge control were measured in both treatments with NM-300K $(3.4 \mathrm{mg} / \mathrm{kg}$ dry sludge, $33.2 \%)$ and silver nitrate $(4.0 \mathrm{mg} / \mathrm{kg}$ dry sludge, 41.3\%) for the first time after 100 days (Figure 1). After 180 days, $51.4 \%$ inhibition of nitrite production was calculated for the NM-300K concentration of $3.4 \mathrm{mg} /$ $\mathrm{kg}$ dry soil. The results after 100 and 180 days for NM$300 \mathrm{~K}$ were in a comparable range to the results with pristine NM-300K after 28 days. Pristine NM-300K was found to inhibit nitrite production by $45 \%$ at $1.67 \mathrm{mg} / \mathrm{kg}$ dry soil (Additional file 1: Table S2). Both concentrations of silver nitrate led to a significant decrease of the nitrite production by $37.9 \%$ to $85.5 \%$ (Figure 1). Effects observed with silver nitrate after 180 days are comparable with those for pristine silver nitrate over the whole test period (28 days).

For STP-spiked sludge (long-term test 2), there was higher nitrite production in the sludge control compared to the control, but the effect had evened out by days 60 and 100, and was inhibited by day 140 (Additional file 6: Table S7). After 32 days, at higher concentrations of $\mathrm{NM}-300 \mathrm{~K}$ and at the tested silver nitrate concentration, the nitrifiers were inhibited (Figure 2). With increasing incubation time, effects also occurred at lower concentrations of NM-300K (except $0.3 \mathrm{mg} / \mathrm{kg}$ dry soil) and continued to increase until the end of the test. Nitrite production was inhibited at high soil concentrations of $9.0 \mathrm{mg} / \mathrm{kg}$ dry soil for NM-300K (25\%) and $3.4 \mathrm{mg} / \mathrm{kg}$ dry soil for silver nitrate (39\%) after 32 days. Concentrationresponse relationships for NM-300K were also found on days 60,100 and 140 in the two highest test concen-

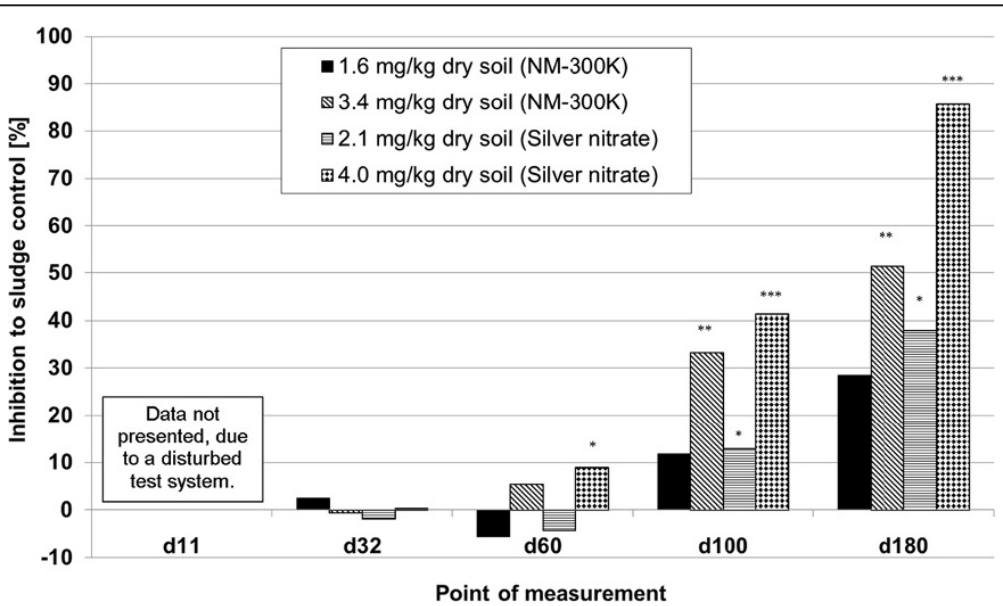

Figure 1 Long-term test 1 - inhibition of the nitrite production in comparison to the sludge control. ${ }^{*} 0.05 \geq P \geq 0.01$; ${ }^{* *} 0.01 \geq$ $P \geq 0.001 ;{ }^{* * *} P \leq 0.001$ 


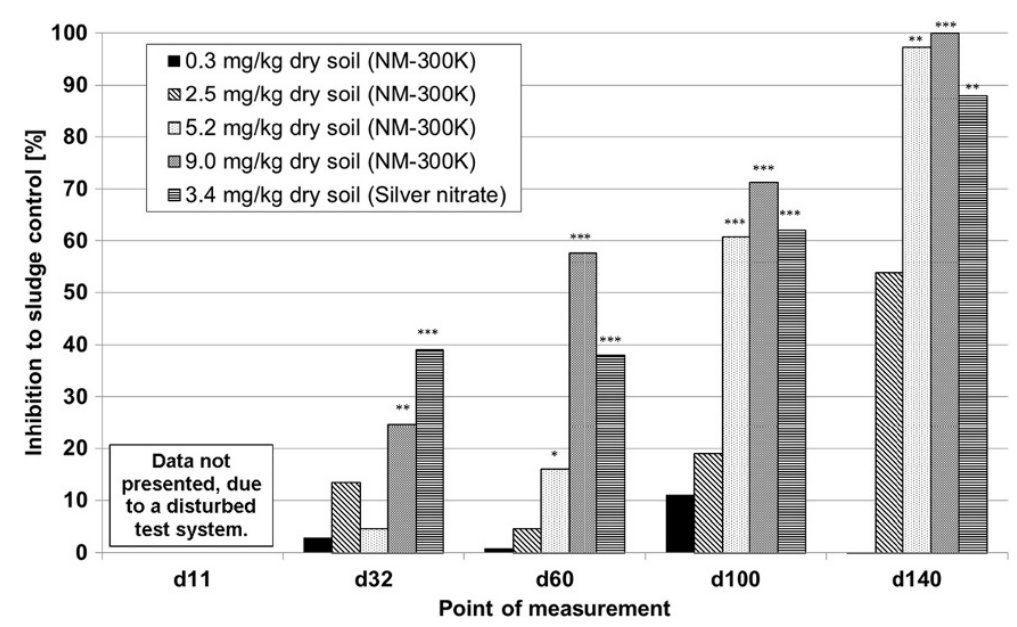

Figure $\mathbf{2}$ Long-term test 2 - inhibition of the nitrite production in comparison to the sludge control. ${ }^{*} 0.05 \geq P \geq 0.01 ;{ }^{* *} 0.01 \geq$ $P \geq 0.001 ;{ }^{* *} P \leq 0.001$.

trations (Figure 2). By test end, nitrite production was inhibited $52 \%$ at $2.5 \mathrm{mg} / \mathrm{kg}$ dry soil, but the effect was not significant due to the high coefficient of variation. The effect of silver nitrate on nitrite production increased to $88.0 \%$ at a concentration of $3.4 \mathrm{mg} / \mathrm{kg}$ dry soil by day 140 (Figure 2).

The results after 100 and 140 days for NM-300K were comparable to the results for pristine NM-300K after 28 days. Nitrite production was inhibited $45.4 \%$ by NM$300 \mathrm{~K}$ at $1.67 \mathrm{mg} / \mathrm{kg}$ dry soil (Additional file 1: Table S2). The effect of silver nitrate was comparable to the effect of pristine silver nitrate over the whole test period (82.4\% inhibition by $5.0 \mathrm{mg} / \mathrm{kg}$ dry soil after 28 days).

\section{C-transformation}

The validity criterion was met with a coefficient of variation between the replicates of the control of $\leq 15 \%$ at all measurement points for both manually spiked and STPspiked sludge.

The addition of manually spiked sludge increased microbial biomass after 11 days (non-significant due to high coefficient of variation). For the entire test period, no significant differences between the controls with and without sludge were observed (Additional file 6: Table S7). There were no differences between the effects of different concentrations of NM-300K and silver nitrate compared to the sludge control after 11 and 32 days. At the highest concentration of silver nitrate $(4.0 \mathrm{mg} / \mathrm{kg}$ dry soil), $21.7 \%$ inhibition of microbial biomass was determined after 60 days (Figure 3). At all concentration levels of NM-300K and silver nitrate, microbial biomass was inhibited $23.3 \%$ to $30.8 \%$ by day 100 (Figure 3 ). After 180 days, microbial biomass was significantly inhibited by all concentrations of NM-300K and silver nitrate on one level (approximately $42 \%$ ). This effect is similar to the effect of pristine NM-300K, where inhibition of microbial biomass of $21 \%$ to $44 \%$ at concentrations of 1.67 to $5.0 \mathrm{mg} / \mathrm{kg}$ dry soil for NM-300K was observed. Effects observed with silver nitrate after 180 days were only comparable with those found for pristine silver nitrate after $24 \mathrm{~h}(60 \%$ inhibition at $5.0 \mathrm{mg} / \mathrm{kg}$ dry soil).

For STP-spiked sludge at test start (day 11), the comparison of both controls showed that microbial biomass was stimulated by the addition of sewage sludge, but there was no influence by NM-300K or silver nitrate. After 32 days, that stimulation by sewage sludge had slightly decreased while NM-300K at 0.3 and $2.5 \mathrm{mg} / \mathrm{kg}$ dry soil (15.1\% and $20.0 \%)$ showed statistically different inhibition of microbial biomass (Additional file 6: Table S7). No inhibition was observed in the higher soil concentrations of NM-300K (5.2 and $9.0 \mathrm{mg} / \mathrm{kg}$ dry soil) or the replicate with silver nitrate. At day 60, a concentrationeffect relationship was determined for the 2.5 and $5.2 \mathrm{mg}$ NM-300K/kg dry soil concentrations (25\% inhibition) and

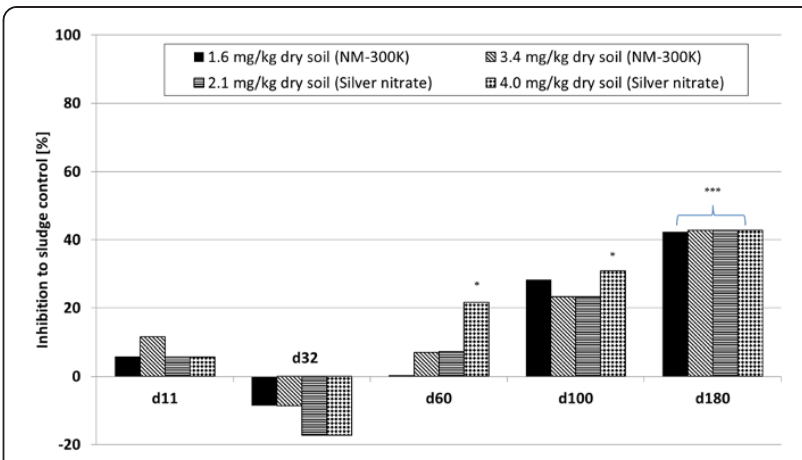

Figure 3 Long-term test 1 - inhibition of the microbial biomass in comparison to the sludge control. ${ }^{*} 0.05 \geq P \geq 0.01 ;{ }^{* *} 0.01 \geq$ $P \geq 0.001 ;{ }^{* * *} P \leq 0.001$. 
$9.0 \mathrm{mg} / \mathrm{kg}$ dry soil (50\% inhibition). These effects were also observed for pristine NM-300K at day 7 and day 28 . Silver nitrate inhibited microbial biomass by $43.3 \%$ (Figure 4). The inhibitory effect of silver nitrate at day 60 was also comparable with the effect found in the test with pristine silver nitrate after $24 \mathrm{~h}$ (60\% inhibition at $5.0 \mathrm{mg} /$ kg dry soil). With progressive test duration, inhibition caused by low soil concentrations of NM-300K ( 0.3 and $2.5 \mathrm{mg} / \mathrm{kg}$ dry soil) and silver nitrate decreased (day 100) to a level similar to that of the sludge control. By day 100, only the two highest soil concentrations of NM-300K continued to inhibit microbial biomass, by $52 \%$ and $64.4 \%$ (Figure 4). At the end of the test, after 140 days, no inhibition was observed.

\section{Functional microbial diversity}

After 100 days, soil microbial diversity was investigated by enzyme activity. In long-term test 1 (manually spiked sludge), the replicates containing NM-300K or silver nitrate showed statistically significant differences compared with the sludge control. Investigated parameters of the 'C-cycle' were strongly inhibited by both soil concentrations of NM-300K and silver nitrate. Investigated parameters of the 'P-cycle' were unaffected while parameters of the 'N-cycle' were significantly inhibited by NM$300 \mathrm{~K}$ and silver nitrate in the highest test concentration.

Microbial diversity was also affected by NM-300K and silver nitrate when delivered through STP simulation (long-term test 2). The C-cycle was significantly stimulated by a concentration of NM-300K of $9.0 \mathrm{mg} / \mathrm{kg}$ dry soil and also by silver nitrate. The P-cycle was affected by soil concentrations of NM-300K from 2.5 to $9.0 \mathrm{mg} /$ $\mathrm{kg}$ dry soil within a concentration-effect relationship (Additional file 7: Figure S1). The results found through STP-spiked sludge for the P-cyle and N-cycle were not comparable with manually spiked sludge. However, the
$\mathrm{N}$-cycle was inhibited by NM-300K concentrations of 2.5 to $9.0 \mathrm{mg} / \mathrm{kg}$ dry soil, and a concentration-effect relationship was detected, similarly to manually spiked sludge (Additional file 8: Figure S2). Unlike in manually spiked sludge, silver nitrate did not inhibit the $\mathrm{N}$-cycle in the second test, although comparable concentrations were tested.

\section{Hazard assessment}

Due to the lack of a PEC for NM-300K, no classic risk characterisation could be performed. Instead, a hazard assessment was conducted, and the maximum concentration of AgNPs in sewage sludge in which no effects are expected on the organisms of the terrestrial ecosystem was determined.

The results of the conducted tests show good comparability between the effects of pristine NM-300K and long-term tests with NM-300K (application via sewage sludge) on soil microorganisms and in further tests with plants (data not shown). In both test types (with pristine NM-300K and in long-term tests), nitrifiers were the most sensitive to NM-300K. Due to the larger dataset from tests with pristine NM-300K (more concentrations tested; thus, a NOEC and $\mathrm{EC}_{10}$ could be determined), we decided to prepare the hazard assessment based on the results from tests with pristine NM-300K.

From our results, a PNEC was calculated with consideration for the effects of AgNPs on different trophic levels (microorganisms in the soil, plants and earthworms). The calculation was based on the lowest soil concentration causing an organism response. These organisms were the nitrifiers, with an $\mathrm{EC}_{10}$ after 28 days (end of test) of 0.5 $\mathrm{mg} / \mathrm{kg}$ dry soil for NM-300K.

The hazard assessment was based on $\mathrm{EC}_{10}$ values of at least three tests with three different organisms from three different trophic levels, which resulted in an assessment

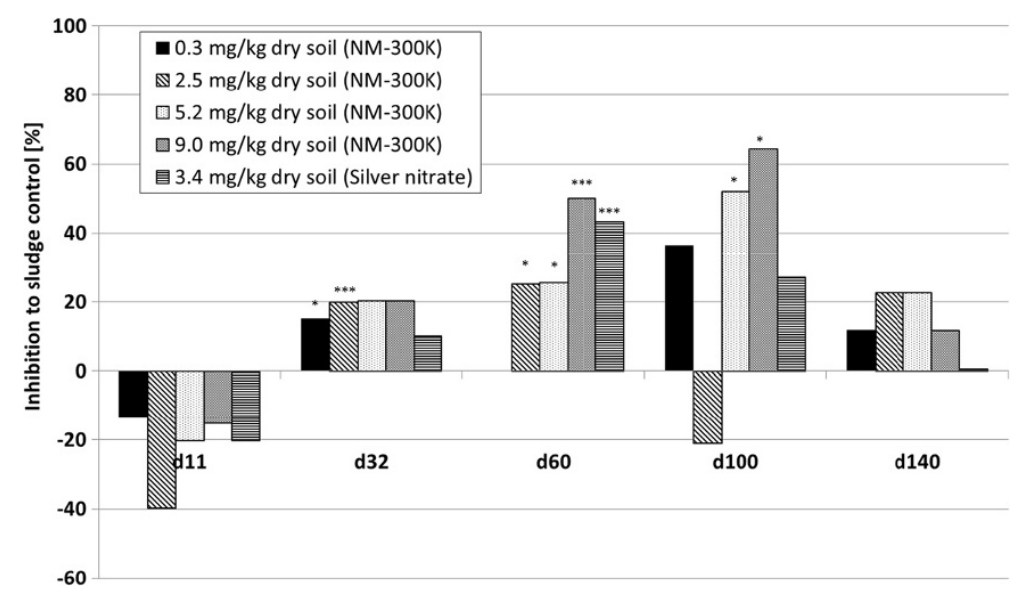

Figure 4 Long-term test 2 - inhibition of the microbial biomass in comparison to the sludge control. ${ }^{*} 0.05 \geq P \geq 0.01$; ${ }^{* *} 0.01 \geq$ $P \geq 0.001 ;{ }^{* * *} P \leq 0.001$. 
factor of 10. On this basis, a PNEC in soil of $0.05 \mathrm{mg} / \mathrm{kg}$ dry soil was calculated for NM-300K. The calculated PNEC was transferred to the sludge pathway. Based on the German sewage sludge ordinance ( 5 tons of dry sludge can be applied per hectare in 3 years, see the 'Methods' section), $1.67 \mathrm{~g}$ dry sludge/kg dry soil could be applied as sludge to the test soil. The concentration of NM-300K that can be applied via $1.67 \mathrm{~g}$ dry sludge without passing the limit of $0.05 \mathrm{mg} / \mathrm{kg}$ dry soil was calculated. The PNEC in soil (for the sewage sludge pathway) corresponds to a concentration of $30 \mathrm{mg} / \mathrm{kg}$ dry sludge of NM-300K in a single application.

\section{Discussion}

\section{Fate and behaviour of NM-300K in a STP}

The test materials were spiked into sewage sludge in two different ways, manually over $2 \mathrm{~h}$ and through the simulation of a STP over 10 days. Simulating a STP leads to homogeneous distribution of silver in soil more so than manual spiking. However, the main advantage of testing by manual spiking was the faster incorporation of silver into sludge $(2 \mathrm{~h})$. Independent of the application method (two tests with manual spiking and two tests with a simulation of a STP), the results were reproducible and comparable. At environmentally relevant concentrations, over $90 \%$ of the introduced NM-300K was absorbed into the sludge (either in the nanoparticulate or ion form we were unable to differentiate). Micro-organism degradation activity in the sludge was not affected by the addition of NM-300K at any stage. These results are supported by studies described in the literature.

Batch experiments by Tiede et al. [20] also found that after $6 \mathrm{~h}$ of contact time between AgNPs (particle size 20 to $60 \mathrm{~nm}$ ) and sludge, more than $90 \%$ of the added AgNPs were found in the sludge (at 0.5, 5 and $10 \mathrm{mg} / \mathrm{L}$ ). Less than 10\% of the AgNPs were found in the supernatant. The interactions were explained by absorption of particles to sludge. Absorption and precipitation reactions of silver ions from AgNPs with chloride, sulphide, and organic material are possible reasons for the interaction of sewage sludge and AgNPs.

Our fate results are also supported by two other studies [21,22]. In a study by Kaegi [21] using model STPs, 85\% of the AgNPs added to the denitrification process were detected in sludge over 43 days. Of the remaining AgNPs, 5\% were in the effluent and another 5\% were detected in the STP. The remaining 5\% of the AgNPs could not be detected and were absent from the mass balance [21]. A study by Shafer et al. [22] about the fate of silver in STPs also confirmed our results. Here it has been shown that $92 \%$ to $99 \%$ of the inlet concentration of silver was removed by the STP. Other experiments showed that independent of the AgNP properties (size and coating), particles absorb to the sludge by around $90 \%[23,24]$, which we also observed.

The mentioned studies confirm the results of the investigations on the fate of the AgNP NM-300K in sewage sludge. Due to the high absorption of AgNPs to sludge, regardless of size or coating, application of sewage sludge to agricultural land will result in deposition of AgNPs.

The respiration inhibition test [19] showed that NM$300 \mathrm{~K}$ was less toxic than silver nitrate (NM-300K: $\mathrm{EC}_{50}$ 43 to $67 \mathrm{mg} / \mathrm{L}$; silver nitrate: $\mathrm{EC}_{50} 2$ to $\left.3 \mathrm{mg} / \mathrm{L}\right)$. In a study by Choi et al. [25], the effect of AgNP (average particle size $14 \mathrm{~nm}$, stabilized with PVA), silver chloride colloids and silver nitrate to the nitrifiers in sewage sludge was studied. At a concentration of $1 \mathrm{mg} / \mathrm{L}$, nitrifying organisms were inhibited by $86 \%$. Silver chloride colloids and silver nitrate inhibited the nitrifiers by $46 \%$ and $42 \%$, respectively. The effect caused by silver nitrate was in a comparable range to our results, while the AgNP inhibition effect was stronger. Differences can be explained not only by different properties of the applied AgNP but also by the preparation of the sewage sludge. Choi et al. [25] conducted tests with enriched nitrifiers and washed sewage sludge, whereas in the tests with NM-300K, the sludge was only washed once with isotonic solution. It cannot be excluded that different amounts of substances reacting with AgNP were present due to the different preparation procedures. Another study of Choi et al. [26] showed that small amounts of sulphide can decrease the inhibitory effect of AgNPs, delivering an explanation for the decreased toxicity in the tests with NM-300K.

The respiration inhibition test was conducted prior to the simulated STPs to measure the potential influent concentration and its effect on sludge microorganisms. Our results indicate that the OECD 209 (1984) respiration inhibition test represents a good test for a first observation and allows extrapolation of effects which might occur in a simulated sewage treatment plant.

\section{Effects of NM-300K and silver nitrate in soil added via spiked sludge (long-term tests)}

Comparison of the tests shows that the effects caused by the pristine material over 28 days occurred earlier than in the long-term tests with sludge over 140 or 180 days. The sewage sludge masked the effect of NM-300K and silver nitrate until the sludge was degraded by microorganisms.

Observations of microbial biomass over time in manually spiked sludge match those of the pristine material. The pristine material leads to inhibition of microbial biomass at the beginning of the test, which declined until no effect was observed at test end (28 days). Through STP, no inhibition was observed at test start due to the masking of NM-300K and silver nitrate by 
sludge. After 60 days, the easily degradable portion of the sludge was degraded and the NM-300K and silver nitrate inhibited microbial biomass. The observed effects decreased (100 days) until no effect was observed at test end (140 days). Effects of STP-spiked sludge occurred later in the test, and lack of full recovery of microbial biomass was most likely because of the limited duration of the experiment (max. 180 days). Different seasonal test start dates (manual spiking: July 2011, STP simulation: March 2012) and subsequent field sampling times and vegetation differences may have affected the composition of the soil microflora that resulted in the different time course.

The obtained results show that there is no difference in effects between manually spiked sewage sludge and sludge spiked via a STP. The main advantage of spiking via a STP is the homogeneous distribution of AgNPs in sludge and, after addition of the sludge, in soil. Another advantage is the reaction of AgNPs with the synthetic sewage that allowed potential transformation reactions with compounds of the synthetic sewage to occur. A disadvantage of this method is the long period of spiking over 10 days, while manual spiking needs only $2 \mathrm{~h}$.

The tests with pristine $\mathrm{NM}-300 \mathrm{~K}$ and silver nitrate showed that the highest toxicity was to microorganisms of the soil, the primary destruents. The nitrifiers were the most sensitive organism in tests over 28 days (NM300K: $\mathrm{EC}_{10}$ of $0.5 \mathrm{mg} / \mathrm{kg}$ dry soil). Microbial biomass was affected by $\mathrm{NM}-300 \mathrm{~K}$ in a comparable range $\left(\mathrm{EC}_{10}\right.$ of $1.0 \mathrm{mg} / \mathrm{kg}$ dry soil) after 28 days. In the long-term tests, NM-300K effects on the nitrifiers and the microbial biomass were observed after 60 to 140 days at concentrations of about $1.4 \mathrm{mg} / \mathrm{kg}$ dry soil. The effect concentrations of silver nitrate were in a comparable range for both manually spiked sludge and STP-spiked sludge. Currently there are few studies on the behaviour of AgNPs on microorganisms in soil. Hänsch and Emmerling [11] examined the effect of AgNPs on the microbial biomass and basal respiration activity and the enzyme activity in the soil over 120 days. A commercially available nanosilver spray used to increase plant growth was investigated. Exact data on the particle size, coatings or additives were not listed. AgNP concentrations of $3.2,32$ and $320 \mathrm{mg} / \mathrm{kg}$ dry soil were studied. Due to a lack of information about the AgNP properties, a comparison of the results is difficult. However, concentrations at which effects were observed by Hänsch and Emmerling [11] are comparable with effect concentrations of NM-300K. The microbial biomass was significantly inhibited by increasing concentrations of nanosilver spray, while basal respiration was simultaneously stimulated. The microbial biomass was inhibited (about $50 \%$ ) by a soil concentration of $0.32 \mathrm{mg} / \mathrm{kg}$, which is comparable to effects caused by pristine NM-300K and those found in the long-term tests. The soil microbial diversity and enzyme activity were not significantly affected over 120 days. Only leucine aminopeptidase activity showed a weak, non-significant difference between days 0 and 14, suggesting that the $\mathrm{N}$-cycle was most sensitive [11]. This is supported by measurements of soil microbial diversity carried out during the long-term tests.

Shin et al. [27] observed inhibition of the soil enzyme activity by AgNPs. Four soil enzymes of the nutrient cycle (urease, acid phosphatase, arylsulphatase, $\beta$-glucosidase) and two soil enzymes involved in general microbial activity (dehydrogenase and fluorescein diacetate hydrolase) were examined. Citrate-stabilised AgNPs with an average particle size of $9.9 \mathrm{~nm}$ (measured by transmission electron microscopy (TEM)) were considered. The enzyme activity was determined on days 0,1 and 7 . Urease activity was reduced at $1 \mathrm{mg} / \mathrm{kg}$ dry soil of AgNPs. The activity of other enzymes studied was also inhibited partly at $10 \mathrm{mg} / \mathrm{kg}$ dry soil (dehydrogenase) and $100 \mathrm{mg} / \mathrm{kg}$ dry soil by the AgNPs. Effects that occurred at test start increased up to day 7 of the test. Through the strong inhibition of urease activity, it was concluded that the nitrogen cycle in soil was strongly influenced by AgNPs. These results fit with the findings that have been observed in our experiments with nitrifiers (potential ammonium oxidation). Even in the long-term tests, the nitrogen cycle was most affected by NM-300K. The nitrifying microorganisms seem to represent the group that reacts most sensitively to AgNPs. The effects of NM-300K in soil observed in this research match the data already published.

\section{Hazard assessment}

It is important for a risk characterisation to consider significant transformation processes and changes of the nanoparticle properties, e.g. in STPs [16]. The effects of these transformation processes in a STP, and also in soil and soil sludge mixtures, and the effects of NM-300K and silver nitrate were tested in long-term tests. A PNEC in soil of $0.05 \mathrm{mg} \mathrm{NM}-300 \mathrm{~K} / \mathrm{kg}$ dry soil was calculated. Via the sludge pathway, this value means sludge containing $30 \mathrm{mg} \mathrm{NM}-300 \mathrm{~K} / \mathrm{kg}$ dry sludge may be applied in a single application to soil before the microorganisms are affected.

The measurement of AgNP in sewage sludge is not provided under the German sewage sludge ordinance. Currently, due to a lack of measurement methods for routine monitoring, it is only possible to perform the determination of the total silver concentration in sewage sludge. A differentiation between silver, AgNPs and silver ions is linked to a complex test methodology (e.g. EDX, SP-ICP-MS or 4F) and unsuitable for routine monitoring of sewage sludge. The lack of adequate techniques for detection and quantification of nanoparticles at environmentally relevant concentrations in complex media hampers the assessment of the results [28]. 
For a preliminary hazard assessment, the effect data obtained with NM-300K were compared with available environmental concentrations and modelled values. The results of the existing data were compared to the total concentration of silver in the soil, even if the proportion of AgNPs of the total silver concentration was expected to be small. Additionally, the results were compared with modelled values for AgNPs in soil introduced within sewage sludge, in which case all AgNPs were included even those that are more or less toxic.

According to a literature review of the German Federal Environmental Agency, the silver concentration in nine municipal sewage treatment plants was determined. A silver concentration between 4 and $26.3 \mathrm{mg} / \mathrm{kg}$ dry sludge was found in 2002. In 2007 the silver concentration in the municipal wastewater treatment plant sludge in Karlsruhe, Pforzheim and Nuremberg was between 12 and $45 \mathrm{mg} / \mathrm{kg}$ dry sludge [29]. In our investigations the sludge from the municipal STP in Schmallenberg had a silver concentration of $1.8 \mathrm{mg} / \mathrm{kg}$ dry sludge. A study by the US EPA showed silver concentrations in the sewage sludge of 1.94 to $856 \mathrm{mg} / \mathrm{kg}$ dry sludge [30]. In this case various sites were studied. High concentrations can be explained by industrial silver entry. From these data, it can be concluded that in sludge of municipal STPs used for agricultural purposes, silver concentrations range from 2 to $45 \mathrm{mg} / \mathrm{kg}$ dry sludge.

For NM-300K, a derived PNEC in soil (via the sludge pathway) of $30 \mathrm{mg} / \mathrm{kg}$ dry sludge, with incorporation of the sewage sludge from municipal wastewater treatment plants, can be classed as a risk to soil organisms. However, this assessment is limited by the missing differentiation between total silver and AgNPs and the fact that the PNEC is for NM-300K only. Nevertheless, it should be kept in mind that the use and release of AgNPs into sludge will increase, and thus, the discrepancy will become smaller.

Model calculations for AgNPs resulted in a PEC for soil undergoing sludge application of $0.0015 \mathrm{mg} / \mathrm{kg}$ dry soil in Europe. For the USA, it was shown that the AgNP concentration increased in the period of 2008 to 2012 from 0.0023 to $0.0074 \mathrm{mg} / \mathrm{kg}$ dry soil [31]. In the present work, for NM-300K, a PNEC for soil of 0.05 $\mathrm{mg} / \mathrm{kg}$ dry soil was determined. The concentration of AgNPs increased annually by about $0.001 \mathrm{mg} / \mathrm{kg}$ dry soil [31]. Assuming a similar continuous rise, the PNEC in soil would be exceeded in approximately 50 years. In this context the behaviour of AgNPs in soil must be considered. Low mobility of AgNPs in soil and repeated application of sewage sludge containing AgNPs to soil can cause an accumulation of AgNPs in soil. One study indicated that $80 \%$ of incorporated AgNPs in soil (particle size 19 $\mathrm{nm}$ ) were not extractable in tests over 70 days, but were a constant source of bioavailable silver [32].
The lack of appropriate measurement techniques and the resulting lack of differentiation between the forms of silver hamper the preparation of a hazard assessment. Even if the amount of AgNPs in the total silver concentration in sewage sludge is marginal, accumulation of AgNPs in the soil to unacceptable levels over time due to repeated farm application of sludge will affect soil microorganisms. Without proper analytical measurement techniques, this issue cannot be fully addressed.

\section{Conclusions}

The following conclusions were drawn:

- Investigations into the effects of NM-300K in soil and the sludge pathway showed for the first time that when applied at environmentally relevant conditions, and even after transformation, AgNP sorption to sludge and aging in soil can have a toxic effect on organisms of the terrestrial ecosystem.

- STP simulations confirmed that at environmentally relevant concentrations, $>90 \%$ of the AgNPs (NM$300 \mathrm{~K})$ remain in the sludge and therefore may not reach the recipient water course.

- After the degradation of sewage sludge, AgNPs (NM-300K) that were absorbed into sewage sludge caused an effect similar to that of pristine NM-300K. This statement applies to dewatered sludge and not to digested sludge.

- The findings confirm that the consideration of transformation and the implementation of long-term tests when performing environmental risk characterisation of AgNPs (and even other nanoparticles) are essential.

- A PNEC in soil of $0.05 \mathrm{mg} / \mathrm{kg}$ dry soil was calculated. Via the sludge pathway, this value means that sludge containing up to $30 \mathrm{mg} / \mathrm{kg}$ dry sludge may be applied in a single application to soil before the microorganisms are affected. However, this assessment is limited by the missing differentiation between total silver and AgNPs and the fact that the PNEC is for NM-300K only.

- Low mobility of AgNPs in soil and repeated application of sewage sludge containing AgNPs to soil can cause an accumulation of AgNPs in soil. The concentration of AgNPs is predicted to increase annually by $0.001 \mathrm{mg} / \mathrm{kg}$ dry soil, indicating that the PNEC in soil would be exceeded in approximately 50 years.

\section{Methods}

\section{Materials}

Test soil

The experiments were carried out using the reference soil RefeSol 01A (sieved $\leq 2 \mathrm{~mm}$ ) as both the test and 
carrier soil [33]. RefeSol 01A is a loamy, medium-acidic and lightly humic sand (Additional file 9: Table S1). RefeSol soils were selected as reference soils by the German Federal Environment Agency (Umweltbundesamt) and are known to be suitable for testing the influence of substances on the habitat function of soils (bioavailability, effects on organisms). RefeSol 01A matches the properties stated in various OECD terrestrial ecotoxicological guidelines (e.g. tests with plants and soil microflora). The soils were sampled in the field and stored in high-grade stainless steel basins with drainage and ground contact on the grounds of Fraunhofer IME in Schmallenberg. During all experiments, red clover was shown on the stored soils and no pesticides were used. Appropriate amounts of soil were sampled 1 to 4 weeks before the test. If the soil was too wet for sieving, it was dried at room temperature to $20 \%$ to $30 \%$ of the maximum water holding capacity $\left(\mathrm{WHC}_{\max }\right)$ with periodic turning to avoid surface drying. If the tests did not start immediately after sieving, the soil was stored in the dark at $4^{\circ} \mathrm{C}$ under aerobic conditions [34].

\section{Sewage sludge}

Sewage sludge, mainly fed with municipal sewage, was freshly gathered in the morning of the experiment at the sewage treatment plant of Schmallenberg (Germany). Previous measurements showed that the silver concentration in the sewage sludge was on average $1.8 \mathrm{mg} / \mathrm{kg}$ dry matter sludge. For dewatering the sludge, the cationic polyacrylamide SEDIFLOC 154 (3F Chimica Deutschland $\mathrm{GmbH}$, Burgthann-Oberferrieden, Germany) was used. Addition of the flocculant was applied strictly according to the instructions of the local sewage treatment plant but varied slightly depending on dry matter concentration and composition of the sewage sludge.

\section{Silver nanoparticle}

The use of the silver nanoparticle NM-300K was stipulated by the OECD Sponsorship Programme [18]. NM$300 \mathrm{~K}$ is a colloidal silver dispersion with a nominal silver concentration of $10 \%(w / w)$ and a particle size of approximately $15 \mathrm{~nm}$ with a narrow size distribution (99\%). A second particle size of $5 \mathrm{~nm}$, which is much less abundant (1\%), was identified by TEM. NM-300K is a mixture of a stabilising agent (NM-300K DIS) comprising 4\% $(w / w)$ each of polyoxyethylene glycerol trioleate and polyoxyethylene sorbitan monolaurate (Tween-20) and AgNPs. The release of ions from NM-300K particles into the matrix under storage conditions was estimated to be less than $0.01 \%(w / w)$ [35].

Silver nitrate was purchased from Merck KGaA, Darmstadt, Germany. The application of the test materials to the test soil is described in Schlich et al. [10] and Hund-Rinke et al. [33], while the application to sewage sludge is described in the 'Methods' section.

\section{Ecotoxicological effects of NM-300K and silver nitrate on soil microorganisms}

In the following, all concentrations refer to the silver $\mathrm{Ag}$ content in the respective test substance. For the assessment of the effect of NM-300K and silver nitrate on the nitrifiers, a combination of two test guidelines was applied. The incubation was carried out in accordance with the OECD Guideline 216 [36]. Due to the high concentration of nitrate from the sewage sludge used in the long-term effect tests, measurement of the nitrate concentration was not performed. Instead, the nitrite concentration was determined with a short-term potential ammonium oxidation test performed in accordance with the ISO Guideline 15685 [37]. Tests were carried out using sieved and spiked soil. Four 250-mL Erlenmeyer flasks per treatment were filled with $25 \mathrm{~g}$ dry matter of spiked soil along with four matching controls. The vessels were incubated in the dark at $20^{\circ} \mathrm{C} \pm 2^{\circ} \mathrm{C}$ for $24 \mathrm{~h}$, after which the mineral test medium was added to make the volume up to $100 \mathrm{~mL}$. The medium consisted of $\mathrm{KH}_{2} \mathrm{PO}_{4}(0.56 \mathrm{mM}), \mathrm{K}_{2} \mathrm{HPO}_{4}(1.44 \mathrm{mM}), \mathrm{NaClO}_{3}$ (5 $\mathrm{mM})$ and $\left(\mathrm{NH}_{4}\right)_{2} \mathrm{SO}_{4}(1.50 \mathrm{mM})$. The slurries were incubated on an orbital shaker at $25^{\circ} \mathrm{C} \pm 2{ }^{\circ} \mathrm{C}$, after which 10 $\mathrm{mL}$ samples were removed at 2 and $6 \mathrm{~h}$, supplemented with $10 \mathrm{~mL}$ of $4 \mathrm{~mol} / \mathrm{L} \mathrm{KCl}$ and filtered, and the nitrite levels in the filtrate determined photometrically (Cary 300 Scan UV-VIS Spectrophotometer, Varian Deutschland GmbH, Darmstadt, Germany) with a wavelength of 530 $\mathrm{nm}$. The effect of NM-300K and silver nitrate on nitrifying microorganisms was examined by the transformation of ammonium after $24 \mathrm{~h}, 7$ days and 28 days.

The carbon transformation (substrate-induced respiration) was determined in accordance with the OECD Guideline 217 [38] using sieved and spiked soil. Four 500-mL Erlenmeyer flasks per treatment were filled with $100 \mathrm{~g}$ dry matter of spiked soil and 2.64 g of a glucose-talc mixture, along with four matching controls. The vessels were incubated in darkness at $20^{\circ} \mathrm{C} \pm 1^{\circ} \mathrm{C}$ for $24 \mathrm{~h}$. Respiration was measured during the incubation with an OxiTop Sensomat system (AQUALYTIC GmbH \& Co., Langen, Germany). Through respiration, oxygen was consumed and the low pressure that occurred was measured. The resulting carbon dioxide was bound to potassium hydroxide and did not interfere with the measurement. From the microorganism respiration rate, the microbial biomass was calculated over the linear time scale in accordance with the ISO Guideline 14240-1 [39].

Three replicates for each control (with or without dispersant) and the different contents of NM-300K and silver nitrate in soil were tested. Both NM-300K and silver nitrate were tested at concentrations of 0.56 , 
1.67, 5.0 and $15.0 \mathrm{mg} / \mathrm{kg}$ dry soil and additionally at $0.19 \mathrm{mg} / \mathrm{kg}$ dry soil for silver nitrate.

Functional microbial diversity was measured by enzyme activity patterns in soil samples in accordance with the ISO/TS Guideline 22939 [40] using fluorogenic substrates as indicators. In this test $2 \mathrm{~g}$ dry matter soil for each concentration was mixed with $200 \mathrm{~mL}$ of ultra-highquality water and homogenised for $3 \mathrm{~min}$ at 9,600 rpm with a homogeniser. Buffer solutions of 2-( $N$-morpholino) ethanesulfonic acid buffer with a $\mathrm{pH}$ of 6.1 and Tris buffer with a $\mathrm{pH}$ of 7.8 were prepared freshly before each use. Two substrates per nutrient cycle $(\mathrm{C}, \mathrm{N}, \mathrm{P})$ with a concentration of $0.1 \mathrm{mmol} / \mathrm{L}$ were tested. As standards, 4methylumbelliferone (MUF) and aminomethylcoumarin (AMC) were used. Tests were performed in 96-well microtiter plates filled with $50 \mu \mathrm{L}$ of soil suspension, 50 $\mu \mathrm{L}$ of buffer and $100 \mu \mathrm{L}$ of substrate. Fluorescence of the standards was measured in plates filled with $50 \mu \mathrm{L}$ of soil suspension, $110 \mu \mathrm{L}$ of buffer and $40 \mu \mathrm{L}$ of MUF or AMC. After the preparation of the microtiter plates, the fluorescence was measured with a Synergy MX spectrophotometer (BioTek Germany, Bad Friedrichshall, Germany) at an excitation wavelength of $355 \mathrm{~nm}$ and an emission wavelength of $460 \mathrm{~nm}$.

\section{Ecotoxicological effects of NM-300K and silver nitrate on sewage sludge microorganisms}

The respiration inhibition test was performed in accordance with the OECD Guideline 209 [19]. It was used as a screening test before the simulation of a sewage treatment plant to gain information about the effects caused by AgNP. The $\mathrm{pH}$ of the sewage sludge was between $7.5 \pm 0.5$. Control measurements were performed in replicates at the beginning and end of the test. As a reference substance, 3,5-dichlorophenol was used. Prior to the test, the sludge was sieved to $\leq 2 \mathrm{~mm}$ and continuously stirred and aerated. When the stirring and aeration were stopped for $15 \mathrm{~min}$, the sludge was able to settle. The supernatant was removed and replaced with Ringer's solution. After that, the sludge was stirred and aerated again. The dry matter content was adjusted to $4.0 \pm 0.4 \mathrm{~g} / \mathrm{L}$ to reach a final dry matter content of $1.6 \mathrm{~g} / \mathrm{L}$ for the test. Synthetic sewage was prepared in accordance with the guideline. The tests were conducted in 1-L Erlenmeyer flasks into which distilled water and synthetic sewage were introduced, followed by the AgNP stock solution and $200 \mathrm{~mL}$ of sludge (dry matter content of $4.0 \mathrm{~g} / \mathrm{L}$ ) in 15 -min intervals to a final volume of $500 \mathrm{~mL}$. The mix was stirred at $300 \mathrm{rpm}$ and aerated with 0.5 to $1 \mathrm{~L} \mathrm{O}_{2} / \mathrm{min}$ for $3 \mathrm{~h}$. The respiration rate was measured in an aliquot of 100 $\mathrm{mL}$ taken every $20 \mathrm{~s}$, within $10 \mathrm{~min}$, with an oxygen electrode.
Long-term effects of NM-300K and silver nitrate in sewage sludge using manually spiked sludge and sewage treatment plant simulation

In accordance with the OECD Guideline 303A [41], a simulation test for aerobic sewage treatment was performed. A lab-scale sewage treatment plant (behrotest ${ }^{\odot}$ Laborkläranlage KLD 4N, behr Labor Technik GmbH, Düsseldorf, Germany) with a denitrification, nitrification and secondary clarifier was used. The validity of the test was reached when $80 \%$ of the introduced DOC concentration $(100 \mathrm{mg} / \mathrm{L})$ had been eliminated by the microorganisms. Six systems were running as a control, four systems with continuous addition (influent) of AgNP at $0.04,0.4,0.8$ and $1.6 \mathrm{mg} / \mathrm{L}$, and another with silver nitrate at $0.4 \mathrm{mg} / \mathrm{L}$. The room temperature was kept at $20^{\circ} \mathrm{C}$ to $25^{\circ} \mathrm{C}$. The oxygen level was controlled to range from 2 to $3.5 \mathrm{mg} / \mathrm{L}$ in the aeration vessel over the whole test period. The STP was set to run with a retention time of $6 \mathrm{~h}$ and a continuous flow of $750 \mathrm{~mL} / \mathrm{h}$ containing a mixture of synthetic sewage, tap water and Ag stock dispersion mixed within a tube system (synthetic sewage was mixed with water and then with the AgNP resulting in a dilution of 1:10). The AgNPs were applied into the denitrification section. Synthetic sewage and AgNP stock dispersion were prepared as a tenfold concentration, as mentioned in the guideline, and stored at $4^{\circ} \mathrm{C}$ in a refrigerator. The $\mathrm{pH}$ of the sewage sludge in the non-aerated and aerated vessels was consistently measured. Continuous reflux from the nitrification section into the denitrification section of $1.75 \mathrm{~L} / \mathrm{h}$ was performed to avoid a decrease of $\mathrm{pH}$. At test start, the sewage sludge was introduced into the STP and tap water was added to end up with a dry matter content of $2.5 \mathrm{~g} / \mathrm{L}$. For 3 days, the sewage sludge was adapted to laboratory conditions by continuously feeding it with just synthetic sewage before the addition of the AgNP for 10 days started. The dry matter content of sludge was determined periodically. The concentration of nitrate, nitrite and ammonia was checked photometrically in the effluent with test kits (Nanocolor, Macherey-Nagel, Düren, Germany), and the flow rate was checked and adjusted if necessary. The DOC was measured daily in the influent flow and effluent.

\section{Manually spiked sludge}

Sewage sludge was freshly gathered from the municipal sewage treatment plant of Schmallenberg, Germany. AgNP and silver nitrate were added to the sludge under aeration and stirring. The procedure was divided into three steps to avoid the inhibition of sludge microorganisms. After a contact time of $2 \mathrm{~h}$, the sludge was dewatered with the flocculant. The supernatant was removed and the sludge centrifuged for $15 \mathrm{~min}$ at 10,500 rpm. Again, the supernatant was removed and the dry matter content of the sludge measured. 
The sludge was added to soil in accordance with the German sewage sludge ordinance, which states that 5 tons per hectare over 3 years can be spread on agricultural areas. Respectively, $1.67 \mathrm{~g}$ of dry matter sludge could be introduced into the soil, under the assumption of a soil depth of $20 \mathrm{~cm}$ and soil density of $1.5 \mathrm{~g} / \mathrm{m}^{3}$. The intended silver concentration was derived from the results of the tests with pristine AgNP but is a concentration with environmental relevance. A silver concentration of 2.5 and $6.0 \mathrm{mg} / \mathrm{kg}$ dry matter soil was intended which corresponds roughly to 1,500 and $3,500 \mathrm{mg} / \mathrm{kg}$ dry matter sludge.

An amount of water to achieve a $\mathrm{WHC}_{\max }$ in soil of $55 \%$ was used to suspend the sludge and to introduce the slurry into soil. The soil was mixed gently to distribute the sludge homogeneously. The test included a control with and without uncontaminated sludge. For each of the AgNP and silver nitrate concentrations and for both controls, two replicates containing $4 \mathrm{~kg}$ of dry matter soil were prepared and incubated. Each replicate was prepared separately. The soil was incubated at $20^{\circ} \mathrm{C}$ under dark conditions in 5 - $\mathrm{L}$ polyethylene containers. Care was taken that the depth of the soil-sludge mixture was less than $15 \mathrm{~cm}$ to avoid anaerobic sections. The containers were closed with a lid with holes for oxygen exchange. The $\mathrm{WHC}_{\max }$ was adjusted to $55 \%$ once per week, and during this procedure, the soil-sludge mixture was again mixed. After 11, 32, 60, 100 and 180 days, the microbial activity was measured with the short-term potential ammonium oxidation test (nitrite formation) and the C-transformation test (microbial biomass). Additionally, after 32 and 100 days, the enzyme activity patterns in soil were measured.

For analytical monitoring, the $\mathrm{pH}$ values were determined regularly with a $0.01 \mathrm{M} \mathrm{CaCl}_{2}$ solution. The $\mathrm{pH}$ values of the soil were measured in the first test after 11, 100 and 180 days in both controls and the highest concentration of each test object. After 32 and 60 days, six samples were taken from different randomised positions in the test container and analysed for total silver concentration.

\section{Sewage treatment plant simulation}

The aim of this experiment was to simulate realistic exposure pathways of NM-300K via sewerage in a municipal STP and sewage sludge on agricultural areas. Six simulated sewage treatment plants were conducted as described in the OECD Guideline 303A [41]. One control, four influent concentrations of NM-300K $(0.04,0.4$, $0.8,1.6 \mathrm{mg} / \mathrm{L})$ and one of silver nitrate $(0.4 \mathrm{mg} / \mathrm{L})$ were dosed into the denitrification section of the STP continuously over 10 days. The influent concentrations lead to final silver concentrations in the sludge of around 240, 2,400, 4,800 and 9,600 mg Ag/kg dry sludge. Based on an entry of $1.67 \mathrm{~g}$ dry sludge/kg dry soil, the targeted concentrations were approximately $0.4,4.0,8.0$ and 16.0 $\mathrm{mg} / \mathrm{kg}$ dry soil for NM-300K and $4.0 \mathrm{mg} / \mathrm{kg}$ dry soil for silver nitrate. The sludge was prepared and introduced into soil as described for manually spiked sludge. In this test only one replicate per control and soil concentration of NM-300K and silver nitrate was applied. First, the sludge was divided into two portions and each was applied to $6 \mathrm{~kg}$ of dry soil. The soil was then pooled, mixed well and stored (in 20-L polyethylene containers) as a replicate. Measurements were conducted with the same tests as described for manually spiked sludge. The test duration was reduced to 140 days after reduced microorganism activity was observed in manually spiked sludge. For STP simulation, at each point of measurement (11, $32,60,100$ and 140 days), $\mathrm{pH}$ values were determined in both controls and each concentration of NM-300K and silver nitrate.

\section{Hazard assessment}

The risk characterisation was based on the directive 'ECHA guidance on information requirements and chemical safety assessment' [42]. Implementation of a classic risk characterisation requires the PEC and PNEC and the ratio of PEC to PNEC.

However, as a PEC for NM-300K was not available, the implementation of the risk characterisation had to be changed. A PNEC was created based on the results of the toxicity of NM-300K on organisms of the terrestrial ecosystem. The effect caused by NM-300K to different trophic levels was considered by observing effects on microorganisms in the soil, plants (data not published) and earthworms [10]. The NOEC or $\mathrm{EC}_{10}$ determined in the test with the most sensitive organism was selected for the determination of the PNEC. Depending on the number of organisms to which the effect of the chemical had been studied, an evaluation factor was applied to the effective concentration. In this study three organisms of three trophic levels were studied (microorganisms, plants, earthworms) that resulted in an evaluation factor of 10. Based on this, the PNEC of NM-300K in soil was determined. Additionally, the PNEC of NM-300K applied to soil via sewage sludge was calculated. The concentration of NM-300K in sludge up to which the PNEC of NM-300K in soil is not exceeded was calculated. Application of the sludge strictly followed the German sewage sludge ordinance according to which 5 tons of dry sludge per hectare over 3 years can be applied to agricultural areas. Considering a soil depth of $20 \mathrm{~cm}$, a soil density of $1.5 \mathrm{~g} / \mathrm{m}^{3}$ and incorporation of the maximum amount of sludge in a single application, a maximum of $1.67 \mathrm{~g}$ of dry sludge could be applied per kilogram of dry soil.

Due to the missing PEC, a limit for NM-300K application to agricultural land via sewage sludge was calculated 
instead of the classic risk characterisation with PEC and PNEC values.

\section{Determination of Ag levels}

Digestion was carried out in accordance with standardised guidelines [43,44], using soil dried at $105^{\circ} \mathrm{C}$ for at least 12 $\mathrm{h}$ until it reached a constant weight. Approximately $3 \mathrm{~g}$ of the homogenised material was mixed with $28 \mathrm{~g}$ of aqua regia and incubated at room temperature for $16 \mathrm{~h}$ without agitation. The mixture was then heated under reflux for 2 $\mathrm{h}$ with glass chips and 1-octanol added to avoid overboiling and foaming. The mixture was cooled to room temperature, made up to $100 \mathrm{~mL}$ and filtered $(0.45-\mu \mathrm{m}$ syringe filter, polyethersulfone membrane, Pall Corporation, Port Washington, NY, USA). The concentration of silver was determined by inductively coupled plasma optical emission spectrometry (ICP-OES) using an IRIS Intrepid II (Thermo Electron, Dreieich, Germany) with a matrix-adjusted calibration carried out for each measurement. Silver was detected at $328.068 \mathrm{~nm}$ and compared to the certified reference material TMDA-70 (certified with $10.9 \mu \mathrm{g} / \mathrm{L} \mathrm{Ag}$ ) as a quality assurance sample. According to the quality assurance requirement, the silver recovery was in the range of $\pm 15 \%$ of the certified value. However, regarding Ag concentrations measured by ICP-OES, the mean recovery (accuracy) and precision of the non-digested CRM TMDA-70 measurements was $101 \% \pm 2.9 \%(n=4)$. The recovery for Merck IV standard solution samples containing 50 $\mu \mathrm{g} / \mathrm{L}$ was $101 \% \pm 2.7 \%(n=4)$ and $94.7 \% \pm 0.7 \%$ for $500 \mu \mathrm{g} / \mathrm{L}$. The instrument was calibrated prior to each measurement series. Silver concentrations in reagent blanks were always below the limit of detection (range 1.34 to $3.51 \mu \mathrm{g} / \mathrm{L}$ ) in the corresponding measurement series. The limit of quantification ranged from 4.48 to $11.7 \mu \mathrm{g} / \mathrm{L}$.

\section{Statistical analysis}

In tests with pristine silver nanoparticles (potential ammonium oxidation, microbial biomass and sewage sludge respiration inhibition), the NOEC were calculated by ANOVA followed by parametric pairwise comparisons of treatments to the control using the Dunnett, Welch, Williams or Fisher exact tests. Probit analysis was performed for the estimate of the $\mathrm{EC}_{x}$ and dose-response curve. Due to fewer treatments and concentrations, the significance of variance between the different treatments was conducted by Student's $t$ tests in the long-term tests. Statistical analysis was carried out using ToxRat ${ }^{\circ}$ Pro v2.10 software for ecotoxicity response analysis (ToxRat Solutions $\mathrm{GmbH}$, Alsdorf, Germany).

\section{Additional files}

Additional file 1: Table S2. Potential ammonium oxidation - results
with NM-300K and silver nitrate.

Additional file 2: Table S3. Microbial biomass - results with NM-300K and silver nitrate.

Additional file 3: Table S4. Respiration inhibition test with sewage sludge - results with NM-300K and silver nitrate.

Additional file 4: Table S5. Analytical monitoring of long term tests.

Additional file 5: Table S6. Fate of NM-300K in the sewage treatment plant conducted previous of long term test 2.

Additional file 6: Table S7. Comparison of the control and the sludge control to present the effect of non contaminated sludge.

Additional file 7: Figure S1. Long-term test 1 - microbial diversity after 100 days.

Additional file 8: Figure S2. Long-term test 2 - microbial diversity after 100 days.

Additional file 9: Table S1. Physico-chemical properties of RefeSol 01A.

\section{Abbreviations}

4F: flow field-flow fractionation; AgNP: silver nanoparticle; DOC: dissolved organic carbon; $\mathrm{EC}_{\mathrm{x}}$ : effect concentration (where $\mathrm{x} \%$ of the organism shows an effect to the test object); EDX: energy-dispersive $X$-ray spectroscopy; NOEC: no-observed-effect concentration; PEC: predicted environmental concentration; PNEC: predicted no-effect concentration; SP-ICP-MS: single-particle inductively coupled plasma mass spectrometry; STP: sewage treatment plant; TEM: transmission electron microscopy.

\section{Competing interests}

The authors declare that they have no competing interests.

\section{Authors' contributions}

KS performed all experiments and drafted the manuscript. TK was responsible for all chemical analysis. KHR participated in the design of the study and was involved in drafting the manuscript. KT was involved in the drafting of the manuscript. All authors read and approved the final manuscript.

\section{Acknowledgements}

This study was funded by the Federal Ministry of Education and Research. It was carried out on behalf of the German Federal Environment Agency (FKZ 370965 416) and financed by federal funds. Language editing by Annabel Clouston was highly appreciated.

\section{Author details}

${ }^{1}$ Fraunhofer Institute for Molecular Biology and Applied Ecology, Auf dem Aberg 1, Schmallenberg 57392, Germany. ${ }^{2}$ Institute of Geological Sciences, Malteserstr. 74-100, Berlin 12249, Germany.

Received: 6 March 2013 Accepted: 2 July 2013

Published: 12 July 2013

\section{References}

1. Woodrow Wilson International Center for Scholars, The Project on Emerging Nanotechnologies: Consumer products. An inventory of nanotechnology-based consumer products currently on the market. www.nanotechproject.org/inventories/consumer.

2. Gottschalk F, Sonderer T, Scholz RW, Nowack B: Possibilities and limitations of modeling environmental exposure to engineered nanomaterials by probabilistic material flow analysis. Environ Toxicol Chem 2010, 29:1036-1048.

3. Bilberg K, Malte H, Wang T, Baatrup E: Silver nanoparticles and silver nitrate cause respiratory stress in Eurasian perch (Perca fluviatilis). Aquat Toxicol 2010, 96:159-165.

4. Farkas J, Christian P, Urrea JA, Roos N, Hassellov M, Tollefsen KE, Thomas KV: Effects of silver and gold nanoparticles on rainbow trout (Oncorhynchus mykiss) hepatocytes. Aquat Toxicol 2010, 96:44-52. 
5. Griffitt RJ, Brown-Peterson NJ, Savin DA, Manning CS, Boube I, Ryan RA, Brouwer M: Effects of chronic nanoparticulate silver exposure to adult and juvenile sheepshead minnows (Cyprinodon variegatus). Environ Toxicol Chem 2012, 31:160-167.

6. Allen HJ, Impellitteri CA, Macke DA, Heckmann JL, Poynton HC, Lazorchack JM, Govindaswamy S, Roose DL, Nadagouda MN: Effects from filtration, capping agents, and presence/absence of food on the toxicity of silver nanoparticles to Daphnia magna. Environ Toxicol Chem 2010, 29:2742-2750.

7. Oukarroum A, Bras S, Perreault F, Popovic R: Inhibitory effects of silver nanoparticles in two green algae, Chlorella vulgaris and Dunaliella tertiolecta. Ecotoxicol Environ Saf 2012, 78:80-85.

8. Tsyusko OV, Hardas SS, Shoults-Wilson WA, Starnes CP, Joice G, Butterfield DA, Unrine JM: Short-term molecular-level effects of silver nanoparticle exposure on the earthworm, Eisenia fetida. Environ Pollut 2012, 171:249-255.

9. Heckmann LH, Hovgaard MB, Sutherland DS, Autrup H, Besenbacher F, Scott-Fordsmand Jj: Limit-test toxicity screening of selected inorganic nanoparticles to the earthworm Eisenia fetida. Ecotoxicology 2011, 20:226-233

10. Schlich K, Klawonn T, Terytze K, Hund-Rinke K: Effects of silver nanoparticles and silver nitrate in the earthworm reproduction test. Environ Toxicol Chem 2013, 32:181-188.

11. Hänsch $M$, Emmerling C: Effects of silver nanoparticles on the microbiota and enzyme activity in soil. Journal of Plant Nutrition and Soil Science 2010, 173:554-558.

12. Benn TM, Westerhoff $P$ : Nanoparticle silver released into water from commercially available sock fabrics. Environ Sci Technol 2008, 42:4133-4139.

13. Geranio $L$, Heuberger M, Nowack B: The behaviour of silver nanotextiles during washing. Environ Sci Technol 2009, 43:8113-8118.

14. Farkas J, Peter H, Christian P, Gallego Urrea JA, Hassellov M, Tuoriniemi J, Gustafsson S, Olsson E, Hylland K, Thomas KV: Characterization of the effluent from a nanosilver producing washing machine. Environ Int 2011 , 37:1057-1062

15. Kaegi R, Sinnet B, Zuleeg S, Hagendorfer H, Mueller E, Vonbank R, Boller M, Burkhardt M: Release of silver nanoparticles from outdoor facades. Environ Pollut 2010, 158:2900-2905.

16. Nowack B, Ranville JF, Diamond S, Gallego-Urrea JA, Metcalfe C, Rose J, Horne N, Koelmans AA, Klaine SJ: Potential scenarios for nanomaterial release and subsequent alteration in the environment. Environ Toxicol Chem 2012, 31:50-59.

17. Wiechmann B, Dienemann C, Kabbe C, Brandt S, Vogel I, Roskoch A: Klärschlammentsorgung in der Bundesrepublik Deutschland. Dessau-Roßlau: Umweltbundesamt; 2012

18. Organisation for Economic Co-operation and Development: Safety of manufactured nanomaterials - Sponsorship Programme for the Testing of Manufactured Nanomaterials. http:/www.oecd.org/science/nanosafety/ sponsorshipprogrammeforthetestingofmanufacturednanomaterials.htm.

19. OECD: OECD Guideline 209, OECD Guidelines of the Testing of Chemicals: Test Guideline 209: Activated Sludge, Respiration Inhibition Test (Carbon and Ammonium Oxidation). Paris: Organisation for Economic Co-operation and Development; 1984.

20. Tiede K, Boxall ABA, Wang X, Gore D, Tiede D, Baxter M, David H, Tear SP, Lewis J: Application of hydrodynamic chromatography-ICP-MS to investigate the fate of silver nanoparticles in activated sludge. Journal of Analytical Atomic Spectrometry 2010, 25:1149.

21. Kaegi $R$, Voegelin A, Sinnet B, Zuleeg S, Hagendorfer $H$, Burkhardt $M$, Siegrist H: Behavior of metallic silver nanoparticles in a pilot wastewater treatment plant. Environ Sci Technol 2011, 45:3902-3908.

22. Shafer MM, Armstrong DE, Overdier JT, Walker MT: Removal, partitioning and fate of silver and other metals in wastewater treatment plants and effluent-receiving streams. Environ Toxicol Chem 1998, 17:630-641.

23. Hou L, Li K, Ding Y, Li Y, Chen J, Wu X, Li X: Removal of silver nanoparticles in simulated wastewater treatment processes and its impact on COD and NH(4) reduction. Chemosphere 2012, 87:248-252

24. Yang Y, Chen Q, Wall JD, Hu Z: Potential nanosilver impact on anaerobic digestion at moderate silver concentrations. Water Res 2012, 46:1176-1184.

25. Choi O, Deng KK, Kim NJ, Ross L Jr, Surampalli RY, Hu Z: The inhibitory effects of silver nanoparticles, silver ions, and silver chloride colloids on microbial growth. Water Res 2008, 42:3066-3074.

26. Choi O, Clevenger TE, Deng B, Surampalli RY, Ross $L \mathrm{Jr}$, Hu Z: Role of sulfide and ligand strength in controlling nanosilver toxicity. Water Res 2009, 43:1879-1886.
27. Shin YJ, Kwak Jl, An YJ: Evidence for the inhibitory effects of silver nanoparticles on the activities of soil exoenzymes. Chemosphere 2012, 88:524-529

28. von der Kammer F, Ferguson PL, Holden PA, Masion A, Rogers KR, Klaine SJ, Koelmans AA, Horne N, Unrine JM: Analysis of engineered nanomaterials in complex matrices (environment and biota): general considerations and conceptual case studies. Environ Toxicol Chem 2012, 31:32-49.

29. Federal Environmental Agency: Beurteilung der Gesamtumweltexposition von Silberionen aus Biozid-Produkten, FKZ 36004020. Berlin: Federal Environmental Agency; 2007.

30. United States Environmental Protection Agency: Targeted national sewage sludge survey statistical analysis. http://water.epa.gov/scitech/wastetech/ biosolids/upload/TNSSS_stat_appendix-A-Apr-2009.pdf.

31. Gottschalk F, Sonderer T, Scholz RW, Nowack B: Modeled environmental concentrations of engineered nanomaterials $\left(\mathrm{TiO}_{2}, \mathrm{ZnO}, \mathrm{Ag}, \mathrm{CNT}\right.$, fullerenes) for different regions. Environ Sci Technol 2009, 43:9216-9222.

32. Coutris C, Joner EJ, Oughton DH: Aging and soil organic matter content affect the fate of silver nanoparticles in soil. Sci Total Environ 2012, 420:327-333.

33. Hund-Rinke K, Schlich K, Klawonn T: Influence of application techniques on the ecotoxicological effects of nanomaterials in soil. Environ Sci Eur 2012, 24:30.

34. ISO: ISO Guideline 18512: Soil Quality - Guidance on Long and Short Term Storage of Soil Samples. Geneva: International Organization for Standardization; 2007.

35. Klein CL, Comero S, Stahlmecke B, Romazanov J, Kuhlbusch TAJ, Doren EV, Temmerman P-JD, Maat J, Wick P, Krug H, Locoro G, Hund-Rinke K, Kördel W, Friedrichs S, Maler G, Werner J, Lingsinger T, Gawlik BM: NM-Series of Representative Manufactured Nanomaterials NM-300 Silver Characterisation, Stability, Homogeneity. JRC Scientific and Technical Reports. Ispra: JRC Scientific and Technical Reports; 2011.

36. OECD: OECD Guideline 216, OECD Guideline for the Testing of Chemicals: Test No. 216: Soil Microorganisms: Nitrogen Transformation Test. Paris: Organisation for Economic Co-operation and Development; 2000.

37. ISO: ISO Guideline 15685: Soil Quality - Determination of Potential Nitrification and Inhibition of Nitrification - Rapid Test by Ammonium Oxidation. Geneva: International Organization for Standardization; 2004.

38. OECD: OECD Guideline 217, OECD Guideline for the Testing of Chemicals: Test Guideline 217: Soil Microorganisms: Carbon Transformation Test. Paris: Organisation for Economic Co-operation and Development; 2000.

39. ISO: ISO Guideline 14240-1: Soil Quality - Determination of Soil Microbial Biomass - Part 1: Substrate-Induced Respiration Method. Geneva: International Organization for Standardization; 1997.

40. ISO: 15O/TS Guideline 22939: Soil Quality - Measurement of Enzyme Activity Patterns in Soil Samples Using Fluorogenic Substrates in Micro-well Plates. Geneva: International Organization for Standardization; 2010.

41. OECD: OECD Guideline 303A, OECD Guidelines for the Testing of Chemicals: Test Guideline 303: Simulation Test - Aerobic Sewage Treatment - A: Activated Sludge Units; B: Biofilms. Paris: Organisation for Economic Co-operation and Development; 2001.

42. ECHA: ECHA Guidance on Information Requirements and Chemical Safety Assessment: Part E: Risk Characterisation. Helsinki: European Chemicals Agency; 2008.

43. ISO: ISO Guideline 11466: Soil Quality - Extraction of Trace Elements Soluble in Aqua Regia. Geneva: International Organization for Standardization; 1995.

44. ISO: DIN EN Guideline 13346: Characterization of Sludges - Determination of Trace Elements and Phosphorus - Aqua Regia Extraction Methods. Berlin: International Organization for Standardization; 2001.

doi:10.1186/2190-4715-25-17

Cite this article as: Schlich et al: Hazard assessment of a silver nanoparticle in soil applied via sewage sludge. Environmental Sciences Europe 2013 25:17. 